May 2002 • NREL/CP-520-31406

\title{
Proposed Reference Spectral Irradiance Standards to Improve Concentrating Photovoltaic System Design and Performance Evaluation
}

\section{Preprint}

D.R. Myers, and K.E. Emery

National Renewable Energy Laboratory

Dr. C. Gueymard

Consultant

To be presented at the $29^{\text {th }}$ IEEE PV Specialists Conference

New Orleans, Louisiana

May 20-24, 2002

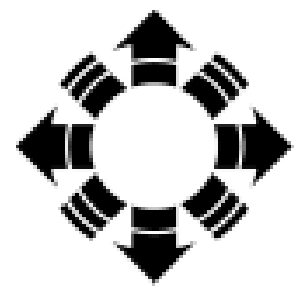

\section{NPEI}

National Renewable Energy Laboratory

1617 Cole Boulevard

Golden, Colorado 80401-3393

NREL is a U.S. Department of Energy Laboratory

Operated by Midwest Research Institute $\bullet$ Battelle $\bullet$ Bechtel

Contract No. DE-AC36-99-G010337 


\section{NOTICE}

The submitted manuscript has been offered by an employee of the Midwest Research Institute (MRI), a contractor of the US Government under Contract No. DE-AC36-99G010337. Accordingly, the US Government and MRI retain a nonexclusive royalty-free license to publish or reproduce the published form of this contribution, or allow others to do so, for US Government purposes.

This report was prepared as an account of work sponsored by an agency of the United States government. Neither the United States government nor any agency thereof, nor any of their employees, makes any warranty, express or implied, or assumes any legal liability or responsibility for the accuracy, completeness, or usefulness of any information, apparatus, product, or process disclosed, or represents that its use would not infringe privately owned rights. Reference herein to any specific commercial product, process, or service by trade name, trademark, manufacturer, or otherwise does not necessarily constitute or imply its endorsement, recommendation, or favoring by the United States government or any agency thereof. The views and opinions of authors expressed herein do not necessarily state or reflect those of the United States government or any agency thereof.

Available electronically at http://www.osti.gov/bridge

Available for a processing fee to U.S. Department of Energy and its contractors, in paper, from:

U.S. Department of Energy

Office of Scientific and Technical Information

P.O. Box 62

Oak Ridge, TN 37831-0062

phone: 865.576 .8401

fax: 865.576.5728

email: reports@adonis.osti.gov

Available for sale to the public, in paper, from:

U.S. Department of Commerce

National Technical Information Service

5285 Port Royal Road

Springfield, VA 22161

phone: 800.553 .6847

fax: 703.605.6900

email: orders@ntis.fedworld.gov

online ordering: http://www.ntis.gov/ordering.htm

Printed on paper containing at least $50 \%$ wastepaper, including $20 \%$ postconsumer waste 


\title{
PROPOSED REFERENCE SPECTRAL IRRADIANCE STANDARDS TO IMPROVE CONCENTRATING PHOTOVOLTAIC SYSTEM DESIGN AND PERFORMANCE EVALUATION
}

\author{
D.R. Myers, K. Emery, National Renewable Energy Laboratory, 1617 Cole Blvd, Golden, CO 80401 \\ Dr. C. Gueymard, Consultant, 174 Bluebird Lane, Bailey, CO
}

\begin{abstract}
The American Society for Testing and Materials (ASTM), the International Electrotechnical Commission (IEC), and the International Standards Organization (ISO) standard solar terrestrial spectra (ASTM G-159, IEC-9043, ISO 9845-1) provide standard spectra for photovoltaic performance applications. Modern terrestrial spectral radiation models and knowledge of atmospheric physics are applied to develop suggested revisions to update the reference spectra. We use a moderately complex radiative transfer model (SMARTS2) to produce the revised spectra. SMARTS2 has been validated against the complex MODTRAN radiative transfer code and spectral measurements. The model is proposed as an adjunct standard to reproduce the reference spectra. The proposed spectra represent typical clear sky spectral conditions associated with sites representing reasonable photovoltaic energy production and weathering and durability climates. The proposed spectra are under consideration by ASTM.
\end{abstract}

\section{INTRODUCTION}

Standard reporting conditions for photovoltaic (PV) device performance specify the standard reference spectrum, American Society for Testing and Materials (ASTM) G-159-98 [1,2]. The references contain direct beam and hemispherical $\left(180^{\circ}\right.$ field of view, sky dome plus ground reflected) spectral distributions. The hemispherical spectrum is incident on a $37^{\circ}$ tilted surface facing south. These spectra were developed in 1982, and revised in 1987. They are based on the work of Bird, Hulstrom, and Lewis [3]. The spectra were computed using the BRITE Monte-Carlo model for 122 individual wavelengths from $305 \mathrm{~nm}$ to $2500 \mathrm{~nm}$ [4]. The spectra were later extended to $4045 \mathrm{~nm}$ using an undocumented simple spectral model. It is not possible to reproduce these spectra, as the BRITE algorithm used seven binary coded data tapes specific to the mainframe computer used for the computations.

Other issues with the current reference spectra have arisen as the terrestrial PV community have come to depend upon these spectra for evaluating technologies. The spectral data is recorded at only 122 irregularly spaced intervals. The equivalent spectral resolution is unclear. There are insufficient data below $350 \mathrm{~nm}$ (and none below $305 \mathrm{~nm}$ ) to characterize the ultraviolet (UV) component, important to materials degradation. The aerosol optical depth chosen appears to be to high to represent conditions prevalent where $\mathrm{PV}$, especially concentrating systems, are most likely to be deployed $[5,6]$.

In the years since these spectra were last revised, more accurate and up-to-date knowledge of atmospheric physics and aerosol properties, and improved radiative transfer models have been developed. These models, and in particular the SMARTS2 model of Gueymard [7], can be used to address the issues above.

\section{PRESENT SPECTRAL STANDARDS}

The present spectral reference standard, ASTM G159-98 is based upon the 1976 U.S. Standard Atmosphere (USSA) profiles of temperature, pressure, air density, and molecular species density specified in 33 layers starting from sea level [8]. Other specified parameters are:

- Absolute air mass (AM) specified AM 1.5 (solar zenith angle $48.19^{\circ}$ ) at sea level

- $\quad$ Receiving surface tilted $37^{\circ}$ from horizontal, "sun facing" (i.e., south in the northern hemisphere)

- Aerosol optical depth, AOD, or "turbidity" of 0.27 at $500 \mathrm{~nm}$ to "correspond to a sea-level visibility of $23 \mathrm{~km}$ ", based on the 1975 work of Shettle and Fenn [9]

- Constant surface albedo (reflectivity) of 0.2 , assuming Lambertian reflectivity

- $\quad$ Total precipitable water vapor content $=1.42 \mathrm{~cm}$

- Total ozone content $=0.34 \mathrm{~atm}-\mathrm{cm}$.

Water vapor and ozone content of the USSA were derived by integrating the 33 layers to produce the total equivalent amounts of these constituents. These conditions in conjunction with the AM0 spectrum of Wehrli and the BRITE Monte Carlo radiative transfer model produced direct normal and total hemispherical spectral irradiance distributions tabulated in the G-159 standard.

The hemispherical spectrum is widely used by the flat-plate PV community for rating modules. The integral of the hemispherical spectrum is $963 \mathrm{~W} / \mathrm{m}^{2}$ rather than $1000 \mathrm{~W} / \mathrm{m}^{2}$. The value of the integrated spectral curves depends on integration technique and can vary by 
$0.1 \%$. The standard states the "modified trapezoidal rule" is used. The spectrum is normalized to integrate to $1 \mathrm{kw} / \mathrm{m}^{2}$ by multiplying the computed spectrum by the ratio $1000 / 963=1.038$

\section{PREVAILING CONDITIONS}

Standard Reporting Conditions (SRC) for flat plate PV devices are $1 \mathrm{~kW} / \mathrm{m}^{2}$ incident (sky plus beam) irradiance, device temperature of $25^{\circ} \mathrm{C}$, and the ASTM G159-98 (formerly ASTM E892) Air Mass 1.5 hemispherical spectrum $[1,2]$. In previous work $[5,6]$, we have shown a "broadband" AOD (0.08) in the southwestern United States occurs when prevailing conditions are near SRC.

The "broadband" (BB) AOD in the NSRDB was computed from the total transmitted direct beam, and not a true spectral AOD [10]. The corresponding AOD at $500 \mathrm{~nm}$ was computed by using the SMARTS2 model (described below) AOD input to achieve the same DNI irradiance that the BB AOD would produce in the NSRDB at an air mass of 1.5. Figure 1 shows the relationship between broadband and monochromatic AOD. (Note: ONLY for the ASTM G-159 conditions specified in the preceding section.) The equivalent monochromatic AOD at $500 \mathrm{~nm}$ for our previous studies is about 0.12 , much lower than the 0.27 specified in ASTM G-159-98.

To further quantify the AOD representative of the climate favorable for the deployment of PV, we examined the National Solar Radiation Data Base (NSRDB) [10] sites with an annual mean daily total direct beam $\geq 6.0 \mathrm{kWh} / \mathrm{m}^{2} /$ day. The mean monochromatic AOD for 15 sites meeting this criterium is 0.085 , as shown in Table 1

Table 1. NSRDB Site data for sites with annual daily mean DNI of at least $6 \mathrm{kWh} / \mathrm{m}^{2} /$ day

\begin{tabular}{cccc}
\hline STATION & $\begin{array}{c}\text { Direct Beam } \\
\text { Kwh/m } / \text { day }\end{array}$ & $\begin{array}{c}\text { AOD } \\
\text { @ 500 } \\
\text { nm }\end{array}$ & BB AOD \\
\hline Daggett, CA & 7.50 & 0.087 & 0.058 \\
Las Vegas, NV & 7.10 & 0.105 & 0.068 \\
Tucson, AZ & 7.00 & 0.099 & 0.065 \\
Phoenix, AZ & 6.80 & 0.142 & 0.090 \\
Prescott, AZ & 6.80 & 0.074 & 0.050 \\
Alamosa, CO & 6.80 & 0.029 & 0.024 \\
Albuquerque, NM & 6.70 & 0.074 & 0.050 \\
Tonopah, NV & 6.70 & 0.082 & 0.055 \\
El Paso, TX & 6.70 & 0.118 & 0.076 \\
Flagstaff, AZ & 6.40 & 0.074 & 0.050 \\
Reno, NV & 6.20 & 0.091 & 0.060 \\
Cedar City, UT & 6.20 & 0.074 & 0.050 \\
Pueblo, CO & 6.10 & 0.074 & 0.050 \\
Tucumcari, NM & 6.10 & 0.099 & 0.065 \\
Ely, NV & 6.00 & 0.050 & 0.036 \\
\hline Regional Avg. & $<6.61>$ & $<0.085>$ & $<0.056>$ \\
\hline
\end{tabular}

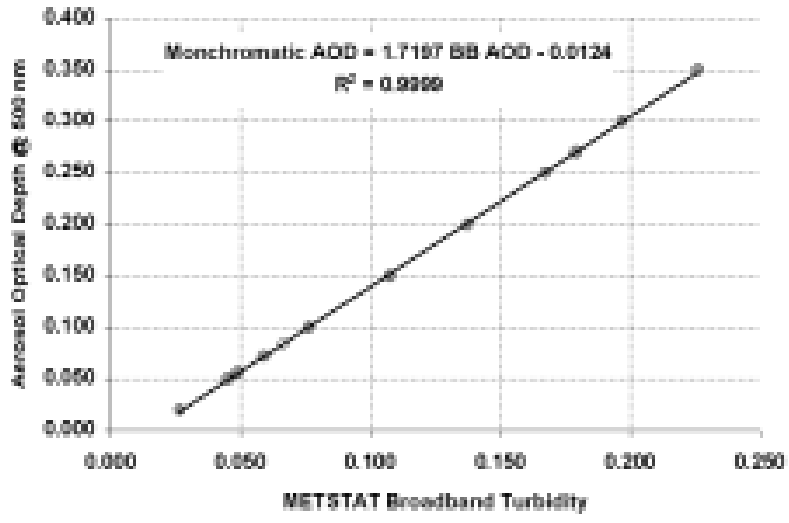

Fig. 1. Monochromatic AOD at $500 \mathrm{~nm}$ versus METSTAT (NSRDB) "Broadband" AOD, which produce identical direct normal irradiance for G-159 conditions.

\section{SMARTS2 MODEL}

Gueymard developed SMARTS2, (Spectral Model for Atmospheric Transmission of Sunshine) based on parameterizations extinction processes modeled in detail by MODTRAN [11]. A choice of six extraterrestrial spectra with 2002 wavelengths between $280 \mathrm{~nm}$ and $4000 \mathrm{~nm}$ are available. All are based on extraterrestrial spectra available in MODTRAN version 4 (MODTRAN4). The spectral step size of the extraterrestrial spectra is 0.5 $\mathrm{nm}$ from $280 \mathrm{~nm}$ to $400 \mathrm{~nm}, 1 \mathrm{~nm}$ from $400 \mathrm{~nm}$ to a transitional wavelength at $1702 \mathrm{~nm}$, and $5 \mathrm{~nm}$ from $1705 \mathrm{~nm}$ and thereafter. The effective spectral resolution for SMARTS2 at each computed point is equivalent to the wavelength interval (e.g., $0.5 \mathrm{~nm}, 1 \mathrm{~nm}$, or $5 \mathrm{~nm}$ )

SMARTS2 incorporates ten reference atmospheric profiles, including the USSA. The model accounts for Rayleigh scattering and ozone, nitrogen dioxide, mixed gases, 10 pollutant gases, water vapor, and aerosol extinction properties. The program provides much of the flexibility of MODTRAN4 with improved accuracy over the NREL SPCTRAL2 model.

Because of the accuracy and ease of use of SMARTS2 with respect to MODTRAN, we selected it as the atmospheric transmission model to generate proposed revised spectral distribution standards. We propose to make the SMARTS2 model available as an adjunct standard to the proposed revised spectral standards, so that any user will be able to generate the reference (and other spectra) at the user's convenience.

\section{PROPOSED STANDARD SPECTRA}

SMARTS2 inputs to produce the proposed reference spectra are shown in Table 2. The conditions for the proposed spectra match those for the present spectra in all but three parameters. First, the aerosol optical chosen (0.084) is very close to the that of prevailing conditions derived from the review of broadband data bases (shown in Table 1). Second, rather than a 
spectrally constant albedo of 0.2 , a spectral albedo file for light sandy soil is used. Finally, rather than the default carbon dioxide concentration of the 1976 reference atmosphere (330 parts per million by volume) we propose using the currently accepted value of $370 \mathrm{ppm}$.

Using 0.084 rather than 0.085 as the AOD, the hemispherical spectrum for the $37^{\circ}$ tilted south facing surface integrates to $1000.37 \mathrm{~W} / \mathrm{m}^{2}$, thus removing the need to scale the reference spectrum for STC. Figure 2 presents the proposed spectra, as well as the present spectra for comparison.

Note that an uncertainty in measurements of AOD of \pm 0.02 represents very high quality measurements.

Table3. SMARTS2 parameters to generate proposed direct normal and hemispherical reference spectrum.

\begin{tabular}{ll}
\hline SMARTS2 Parameter & \multicolumn{1}{c}{ Value } \\
\hline Pressure mode (1 = pressure and altitude) & 1 \\
Station Pressure (mb) \& altitude $(\mathrm{km})$ & $1013.25,0.0$ \\
Use a default atmosphere & 1 \\
Default Standard Atmosphere Profile & 'USSA' \\
Default Water Vapor from Profile & 1 \\
Default Ozone from Profile & 1 \\
No pollution modifications (default to profile) & 1 \\
Carbon Monoxide volume mixing ratio (ppmv) & 370 \\
Gueymard Extraterrestrial spectrum & 1 \\
Aerosol Profile to Use & 'S\&F_RURAL' \\
Aerosol mode: optical depth at 500 nm & 0 \\
Aerosol Optical Depth @ 500 nm & 0.084 \\
Spectral Albedo file : Light Sandy Soil & 38 \\
Specify tilt calculation & 1 \\
Albedo file, Tilt, Azimuth & $38,37,180$ \\
Start, stop nm, radius vector, Solar Constant & $280,4000,1,1367$ \\
Spectral output file print mode (Spreadsheet) & 2 \\
Print limits, start, stop, minimum step size nm & $280,4000,0.5$ \\
Number of output variables to print & 2 \\
Output 8 = Hemispherical tilt; & 8,9 \\
9 = direct normal + circumsolar & 1 \\
Circumsolar calculation mode & $0,2.9,0$ \\
Receiver Slope, View, Limit half angles & 0 \\
Smooth function mode $(0=$ none) & 0 \\
Illuminance calculation mode (0 = none) & 0 \\
UV calculation mode $(0$ = none) & 2 \\
Solar Geometry mode (2 = Air Mass) & 1.5 \\
Air mass value &
\end{tabular}

The proposed hemispherical tilt spectrum differs only slightly from the previous hemispherical tilt spectrum at the presently tabulated data points. Figure 3 shows the differences between the present and proposed hemispherical spectra at the tabulated points for the present spectrum.

The average percent-of-reading difference between the present and proposed hemispherical spectra between $400 \mathrm{~nm}$ and $1100 \mathrm{~nm}$ is $3.0 \%$. This difference is smaller than the uncertainty (typically about $5 \%$ ) in the best spectral irradiance measurements that can be made by a very competent laboratory. The average difference in absolute spectral intensity over all tabulated data points is $0.024 \mathrm{~W} / \mathrm{m}^{2} / \mathrm{nm}$

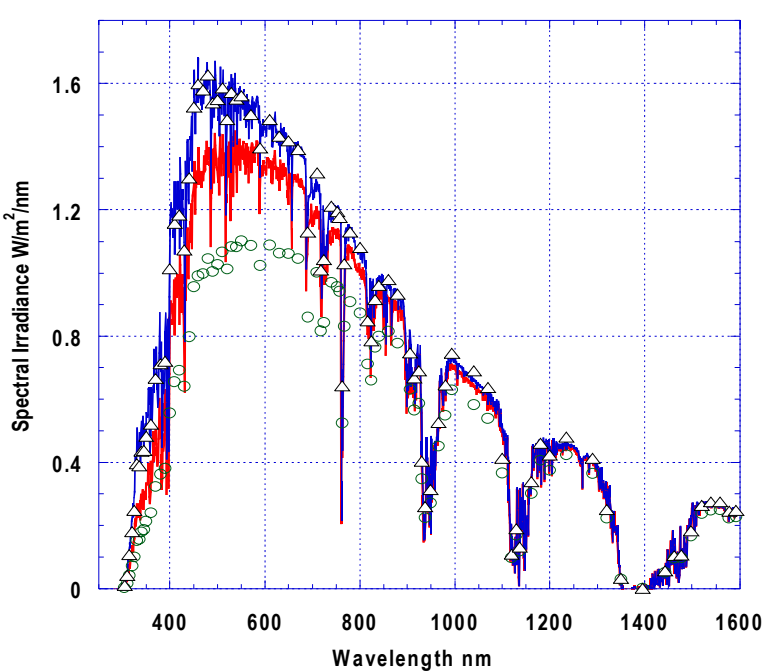

Fig. 2. Existing (symbols) and proposed (lines) ASTM direct normal and hemispherical tilted spectra. Upper line is proposed hemispherical tilt, lower line is proposed direct normal. Triangles $=1 \mathrm{~kW} / \mathrm{m}^{2}$ normalized hemispherical tilt, circles $=$ direct normal reference tabular data. Differences beyond $1400 \mathrm{~nm}$ are minimal.

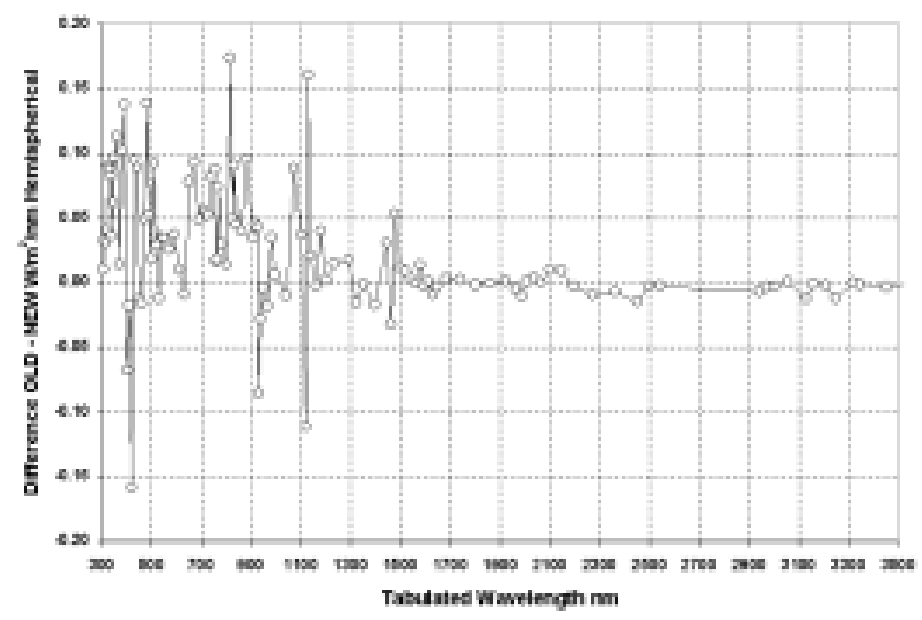

Fig. 3. Absolute difference in Watts per square meter per nanometer between present and proposed reference hemispherical spectra at tabulated data points

\section{DIRECT NORMAL REFERENCE SPECTRA}

The lower monochromatic AOD at $500 \mathrm{~nm}$ selected for the proposed reference conditions results in a greater change in the direct normal spectral irradiance. The resulting direct spectrum is in better agreement with (1) measured spectra at near SRC, and (2) the measured broadband value of direct beam data at near SRC $[5,6]$. 
The present direct normal spectrum integrates to $763 \mathrm{~W} / \mathrm{m}^{2}$. The proposed direct normal spectrum integrates to $900.14 \mathrm{~W} / \mathrm{m}^{2}$. This is $50 \mathrm{~W} / \mathrm{m}^{2}$ greater than the $850 \mathrm{~W} / \mathrm{m}^{2}$ test conditions developed for the Photovoltaic for Utility Scale Applications (PVUSA) concentrator acceptance tests [12]. It is also larger than the $836 \mathrm{~W} / \mathrm{m}^{2}$ direct normal irradiance value arrived at when analyzing prevailing conditions near SRC in our previous work $[5,6]$. These are differences of less than $7 \%$ with respect to PVUSA and our previous work.

The present direct normal spectrum has occasionally been normalized to an equivalent total irradiance of $1000 \mathrm{~W} / \mathrm{m}^{2}$ in order to evaluate concentrator systems. However, the correction factor $(1000 / 763=1.31)$ for this normalization produces spectral irradiance values in the infrared that exceed the extraterrestrial spectrum and are not meaningful [13].

\section{STATUS OF THE PROPOSED REVISED STANDARD SPECTRA}

The ASTM consensus process requires three levels of approval. The standard is drafted, discussed, and reviewed at the subcommittee level. Once considered in a suitable form, ASTM conducts a subcommittee ballot. Members vote affirmative, negative (with substantive supporting information), or abstain.

Every negative requires discussion by the subcommittee, and revisions are made to accommodate persuasive negatives. The revised draft is re-balloted until approved at the subcommittee level. Upon subcommittee approval, the draft is balloted by the entire committee. When approved by the committee, the draft is submitted to the entire ASTM society for review, at which time it is possible further negative responses may occur. Every negative must be resolved, and the process repeats until the draft is finally approved at the society level. The present draft is under subcommittee ballot as of May 2002.

\section{CONCLUSIONS}

We have used a moderately complex radiative transfer model to generate proposed reference spectral irradiance distributions. These spectra are more representative of prevailing conditions where $\mathrm{PV}$ may be effectively deployed. The proposed spectra are based on a quantitative analysis of broadband and spectral measurement data. The proposed hemispherical spectrum on a tilted surface differs only slightly from the existing spectrum, with minimal impact to the flat-plate PV community. The proposed direct normal spectrum is representative of direct normal spectral conditions near SRC for flat-plate PV. The revised spectra have known spectral resolution, smaller, uniform spectral intervals, and more UV data. The SMARTS2 model used to generate spectra is proposed as an adjunct standard to allow for easy reproduction of the spectra, and for generating representative spectra for PV design and performance applications. SMARTS2 is in the public domain, and available from the authors.

\section{ACKNOWLEDGMENTS}

This paper is dedicated to the memory of our colleague, Dr. Richard E. Bird, who passed away 18 April 2002. His contributions have served the PV and solar renewable energy community immeasurably over the past 15 years. Valuable discussions with NREL colleagues Sarah Kurtz, Carl Osterwald, Roland Hulstrom, Martha Symko-Davis, and members of ASTM committees G03 (Weathering and Durability) and E44 (Solar, Geothermal and Alternative Energy) contributed to this effort. The work was performed at NREL under U.S. Department of Energy prime contract \#DE AC36 99G010337.

\section{REFERENCES}

[1] ASTM, "Standard Test Methods for Electrical Performance of Nonconcentrator Terrestrial Photovoltaic Modules and Arrays Using Reference Cells", E1036, Vol. 12.02 (1998)

[2] ASTM Standard Tables for Reference Solar Spectral Irradiance at Air Mass 1.5: Direct Normal and Hemispherical for a $37^{\circ}$ Tilted Surface, Standard G159-99, American Society for Testing and Materials, West Conshohocken, PA. (1999).

[3] Bird, R.E., et al. "Terrestrial solar spectral data sets." Solar Energy 30(6): 563-573. (1983)

[4] Blättner, W.G., et al. "Monte Carlo Studies of the Sky Radiation at Twilight." Appl. Opt. 13: 534-537.(1974).

[5] Kurtz, S., et al., "Outdoor Rating Conditions for Photovoltaic Modules and Systems" Solar Energy Materials and Solar Cells, 62, \#4, pp.379-391 (2000).

[6] Myers, D., et al., "Outdoor Meteorological Broadband and Spectral Conditions for Evaluating Photovoltaic Devices" Proc. $28^{\text {th }}$ IEEE PV Specialists Conference Anchorage AK Sep 18-22 2000.

[7] Gueymard, C., "Parameterized Transmittance Model for Direct Beam and Circumsolar Spectral Irradiance." Solar Energy 71(5): 325-346 (2001).

[8]Anon., U.S. Standard Atmosphere, 1976.

http://nssdc.gsfc.nasa.gov/space/model/atmos/us_standard.html Washington, DC:NOAA/NASA/USAF (1976).

[9] Shettle, E.P. and R. W. Fenn. "Models of the Atmospheric Aerosols and their Optical Properties", Electromagnetic Wave Propagation Panel Symposium, Lyngby, Denmark, 27-31 October, 1975.

[10] NREL "Final Technical Report National Solar Radiation Data Base (1961-1990)", NREL TP 463-5784, NREL, Golden Co. 80401 (1995).

[11] Anderson, G.P., et al. "History of One Family of Atmospheric Radiative Transfer Codes" in Passive Infrared remote Sensing of Clouds and the Atmosphere II. Society of Photo-optical Instrumentation Engineers (1994).

[12] Whitaker, C. M., T. U. Townsend, et al. "Application and validation of a new PV performance characterization method." 26th Photovoltaic Specialists Conf. (1997).

[13] Emery, K. "The Rating of Photovoltaic Performance." IEEE Trans. Electron Dev. 46: 1928-1931 (1999). 


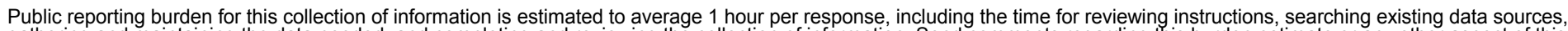

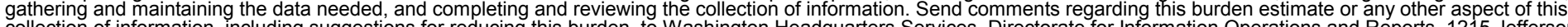
Davis Highway, Suite 1204, Arlington, VA 22202-4302, and to the Office of Management and Budget, Paperwork Reduction Project (0704-0188), Washington, DC 20503.
1. AGENCY USE ONLY (Leave blank)
2. REPORT DATE
May 2002
3. REPORT TYPE AND DATES COVERED
$29^{\text {th }}$ IEEE PVSC-Conference Paper
May 20-24 2002

4. TITLE AND SUBTITLE

Proposed Reference Spectral Irradiance Standards to Improve Concentrating

Photovoltaic System Design and Performance Evaluation: Preprint

6. AUTHOR(S)
D.R. Myers, ${ }^{1}$ K.E. Emery, ${ }^{1}$ and Dr. C. Gueymard ${ }^{2}$

7. PERFORMING ORGANIZATION NAME(S) AND ADDRESS(ES)

1. National Renewable Energy Laboratory, 1617 Cole Blvd, Golden, CO 80401

2. Consultant, 174 Bluebird Lane, Bailey, CO

9. SPONSORING/MONITORING AGENCY NAME(S) AND ADDRESS(ES)

National Renewable Energy Laboratory

1617 Cole Blvd.

Golden, CO 80401-3393

5. FUNDING NUMBERS PVP27401

8. PERFORMING ORGANIZATION REPORT NUMBER

10. SPONSORING/MONITORING AGENCY REPORT NUMBER

NREL/CP-520-31406

11. SUPPLEMENTARY NOTES

12a. DISTRIBUTION/AVAILABILITY STATEMENT National Technical Information Service

U.S. Department of Commerce

5285 Port Royal Road

Springfield, VA 22161 12b. DISTRIBUTION CODE

13. ABSTRACT (Maximum 200 words): This conference paper describes the American Society for Testing and Materials (ASTM), the International Electrotechnical Commission (IEC), and the International Standards Organization (ISO) standard solar terrestrial spectra (ASTM G-159, IEC-904-3, ISO 9845-1) provide standard spectra for photovoltaic performance applications. Modern terrestrial spectral radiation models and knowledge of atmospheric physics are applied to develop suggested revisions to update the reference spectra. We use a moderately complex radiative transfer model (SMARTS2) to produce the revised spectra. SMARTS2 has been validated against the complex MODTRAN radiative transfer code and spectral measurements. The model is proposed as an adjunct standard to reproduce the reference spectra. The proposed spectra represent typical clear sky spectral conditions associated with sites representing reasonable photovoltaic energy production and weathering and durability climates. The proposed spectra are under consideration by ASTM.

14. SUBJECT TERMS: PV; reference spectrum standard; ultraviolet component; atmospheric physics; aerosol optical depth (AOD); spectral model for atmospheric transmission of sunshine (SMARTS2); direct normal spectrum;
15. NUMBER OF PAGES

16. PRICE CODE
17. SECURITY CLASSIFICATION OF REPORT Unclassified
18. SECURITY CLASSIFICATION OF THIS PAGE Unclassified
19. SECURITY CLASSIFICATION OF ABSTRACT Unclassified
20. LIMITATION OF ABSTRACT

UL 